\title{
Physicochemical Property Testing of a Novel Maize Seed Coating Agent and Its Antibacterial Mechanism Research
}

\author{
Qingxiang Deng, Defang Zeng* \\ School of Resource and Environmental Engineering, Wuhan University of Technology, Wuhan, China \\ Email: ${ }^{*}$ 13971066854@163.com
}

Received 15 January 2015; accepted 3 January 2015; published 5 February 2015

Copyright (C) 2015 by authors and Scientific Research Publishing Inc.

This work is licensed under the Creative Commons Attribution International License (CC BY). http://creativecommons.org/licenses/by/4.0/

(c) (i) Open Access

\begin{abstract}
We used the no pollution natural polymer polysaccharide chitosan as the main raw material, which is supplemented by other additives, to prepare a high-efficiency environmental friendly maize seed coating agent. By detecting the seed quality, maize seedling indexes, which include root activity, chlorophyll content and malondialdehyde (MDA) content, and through the results we found that this seed coating agent could improve the photosynthetic capacity and enhance seedling resistance. Laboratory bacteriostasis test and study showed that the antibacterial rate of this seed coating agent has reached more than $88 \%$. Meanwhile, we analyzed and studied the antimicrobial mechanism of the seed coating agent.
\end{abstract}

\section{Keywords}

Maize Seed Coating Agent, Antibacterial, Mechanism Analysis

\section{Introduction}

The history of seed coating agent and seed coating technology research, development, demonstration, popularization and application in China has lasted for over 20 years. The function of seed coating agent played in crop protection has been gradually recognized by people [1] [2]. Seed coating agent is of obvious benefits to control underground pest, kill seed and seedling diseases, promote seedling healthy growth, improve the crop quality and seed germination rate, reduce the use amount of seeds and increase the output and so on [3].

Maize is not only one of China's three major grain crops, but also an important feed and industrial raw materials [4]. The harm of maize leaf blight, sheath blight, head smut and other harmful organisms have great impact "Corresponding author. 
on maize seedling, yield and quality [5]. The seed coated by maize seed coating is an effective method to control the northern maize leaf blight, sheath blight and head smut [6] [7]. Seed coating agent can promote seed germination, prevent and control diseases and insect pests and supply essential nutrients to achieve the purpose of strong seedlings. It can also create a good micro ecological environment [8].

In view of the above problems, we designed a novel maize seed coating agent to replace the traditional maize seed coating agent. We tested the indexes of this seed coating agent to check if it has meet the relevant standards. Then we measured maize seedlings indexes after the maize seed had been coated with the novel maize seed coating agent and the traditional seed coating agent Shileshi respectively, which include root activity, chlorophyll content and MDA content to characterize the maize seedling indexes of life. We also conducted laboratory experiments to analysis the mechanism of the seed coating agent in promoting seedling growth of maize seedlings, enhancing physical indexes, preventing and controlling of maize leaf blight, sheath blight and maize head smut.

\section{Methods and Materials}

\subsection{Experiment Instruments and Materials}

\subsubsection{Main Experimental Instruments}

Electronic analytical balance (JA1003N, Tianjin Shunte Electronic Instrument Co., Ltd., China), electronic constant speed blender (GS-12B, Shanghai Lushuo Real Co., Ltd., China), constant temperature and humidity incubator (LHP-160L, Changzhou Runhua Electrical Appliances Co., Ltd., China), Petri dish ( $\Phi 90$ mm, Shanghai Yuejin Medical Instrument Factory, China), ultrasonic cleaner (KQ-700DE, Shanghai Qiangqiang Instruments Equipment Co., Ltd., China), high temperature blast drying oven (DHG-9078A, Shanghai Shanzhi Instrument Equipment Co., Ltd., China), electrothermal pressure steam sterilizer (XFH-30CA, Dingxinyi Experimental Equipment Co., Ltd., China), microporous test sieve (0.04 mm, Endecotts, Shanghai Guowang Chemical Co., Ltd., China), vacuum microporous filter (TAPS, Beijing Jinghuikaiye Technology Co., Ltd., China), Uv-vis spectrophotometer (UV-3, Shanghai Meipuda Instrument Co., Ltd., China), digital rotational viscometer (NXS-11, Chengdu Instrument Factory, China), spectrophotometer (721S, Shanghai Edge Light Technology Co., Ltd., China), digital electro-thermostatic water bath (HH-4, Honghua Instrument Factory, China).

\subsubsection{Main Experimental Materials}

Chitosan (homemade), film-forming additives (homemade), antifreeze (homemade), microelement nutrient solution (homemade), violet pigments (Hebei Baiwei Biological Technology Co., Ltd., China), deionized water (homemade), maize seeds (Shandong Pingyuanshennong seed industry Co., Ltd., China), Shileshi (traditional maize seed coating agent, Swiss Syngenta Crop Protection Co., Ltd., China), maize northern leaf blight fungus, sheath blight fungus, head smut fungus (Hubei Academy of Agricultural Sciences, China).

\subsection{Preparation of Environmental Friendly Maize Seed Coating Agent}

The above ingredients first mixed with deionized water respectively to be aqueous solution of a certain concentration, then mixed them according to the designed sequence and proportion, finally, stirred completely. This mixed liquid is the product of environmental friendly maize seed coating agent, we marked it as $4 \#-1$.

\subsection{Physicochemical Properties Test of the Maize Seed Coating Agent}

\subsubsection{Physicochemical Properties Requirements of Maize Seed Coating Agent}

According to China's Pesticide Industry Standards, the physicochemical properties and parameters requirements of seed coating agent are in Table 1 [9].

\subsubsection{Testing Methods for Physicohemical Properties of Seed Coating Agent}

1) $\mathrm{pH}$ Value Test

Refer to $\mathrm{pH}$ Value Measurement Method of GB/T 1601-1993 Pesticide.

2) Floating Rate Test

Refer to Measurement Method of GB/T 17768-1999 Standards Specification for the Suspended Seed Coating Agents. 
Table 1. The physicochemical property requirements of seed coating agent.

\begin{tabular}{cc}
\hline Indicators & Requirements \\
\hline $\mathrm{pH}$ Value & $3.8-7.2$ \\
Floating Rate/\% & No less than $90 \%$ \\
Sieve Analysis/\% & No less than $95 \%$ \\
Viscosity & $200-800 \mathrm{mPa} \cdot \mathrm{s}$ \\
Film-Forming Property & qualified \\
Coating Uniformity & No less than $90 \%$ \\
Coating Peeling Rate & No less than $8 \%$ \\
Storage Stability & qualified \\
\hline
\end{tabular}

3) Sieve Analysis Test

Refer to Measurement Method of GB/T 16150-1995 Pesticide Powder, Wettable Powder Fineness.

4) Viscosity Test

Refer to Measurement Method of NY621-2002 Agriculture Industry Standards of Duofuke Suspended Seed Coating Agent.

5) Film-Forming Property Test

Refer to Measurement Method of GB/T 17768-1999 Standards Specifications for Suspended Seed Coating Agents.

6) Coating Uniformity Test

Refer to Measurement Method of GB/T 17768-1999 Standards Specifications for Suspended Seed Coating Agents

7) Coating Peeling Rate Test

Refer to Measurement Method of GB/T 17768-1999 Standards Specifications for Suspended Seed Coating Agents.

8) Storage Stability Test

Refer to Measurement Method of GB/T 17768-1999 Standards Specifications for Suspended Seed Coating Agents.

\subsection{Testing of Different Seed Coating Agents on Maize Seedling Index}

\subsubsection{Testing of Different Seed Coating Agents on Maize Seedling Root Activity}

Plant roots are active absorbing and synthetic organ, the growth and activity level of root influence maize nutrition status and the yield level above ground directly, root activity is an amount that characterize whether plant root is healthy.

The root activity was determined by TTC (three phenyl tetrazolium chloride) method. The testing steps about TTC reduction amount were as follows: took sample of maize root tip for $0.5 \mathrm{~g}$, put the root immersed in a mixed solution containing of $0.4 \%$ TTC and phosphate buffer, then kept it preserving in $37^{\circ} \mathrm{C}$ for three hours, after that, added $2 \mathrm{~mL} \cdot \mathrm{mol} / \mathrm{L}$ sulfuric acid to terminate reaction. Made a blank contrast test at the same time, added sulfuric acid firstly, then added apica sample, other operations were as the same above. Then removed the root, carefully blotted moisture, put it together with $3-4 \mathrm{~mL}$ of ethyl acetate solution into a mortar, added a small amount of quartz sand for full grinding to extract the three phenyl methyl hydrazone. After filtering the extracting liquid, put it into a $10 \mathrm{~mL}$ volumetric flask, then washed with a small amount of ethyl acetate solution for 3 times, put it into test tube to the scale at last. By using spectrophotometer at a wavelength of $485 \mathrm{~nm}$ colorimetric to read the absorbance of OD with blank experiment as reference, through examine the standard curve, we can find the reduction amount of TTC [10]. Finally, the root activity can be calculated by formula.

The calculation formula is as follows:

$$
\text { Root activity }\left(\mathrm{mg} \cdot \mathrm{g} \cdot \mathrm{h}^{-1}\right)=\mathrm{TTC} \text { reduction amount }(\mathrm{mg}) /[\operatorname{root} \text { weight }(\mathrm{g}) \times \operatorname{time}(\mathrm{h})]
$$




\subsubsection{Testing of Different Seed Coating Agents on Maize Seedling Chlorophyll Content}

Chlorophyll is one of the most important pigments related with photosynthesis. It absorbs energy from the light, then the energy is used to convert carbon dioxide into carbohydrates. Photosynthesis is the synthesis process that chlorophyll absorbs light energy to synthesis organic compounds, meanwhile the light energy converts to chemical energy.

Chlorophyll content was determined by spectrophotometry. The testing steps were as follows: 1) The extraction of pigment. Weighed $2 \mathrm{~g}$ fresh maize leaves, put it into a mortar, added a mixture of acetone ethanol (1:1) $10 \mathrm{~mL}$, then added a little calcium carbonate and quartz sand, grinded into homogenate. Then added $80 \%$ acetone $5 \mathrm{~mL}$, put the homogenate into a centrifuge tube, used $80 \%$ acetone to wash mortar. After centrifugation, discarded the pellet, used $80 \%$ acetone to set the supernatant constant volume to $20 \mathrm{~mL}$; 2) The determination of absorbance. Took the above pigment extract $1 \mathrm{~mL}$, added $4 \mathrm{~mL} 80 \%$ acetone to dilute the extract, then put them into the cuvette, set $80 \%$ acetone as control, determined the absorbance value at $663 \mathrm{~nm}$ and $645 \mathrm{~nm}$. Finally, the root activity can be calculated by formula.

The calculation formula is as follows:

$$
\text { Total chlorophyll content }\left(\mathrm{mg} \cdot \mathrm{g}^{-1} \mathrm{FW}\right)=(20.2 \times A 645+8.02 \times A 663) \mathrm{V} / 1000 \times W
$$

where $A 663$ and $A 645$ are respectively the absorbance under the corresponding wave; $V$ for extraction liquid volume; $W$ for leaf weight.

\subsubsection{Testing of Different Seed Coating Agents on Malondialdehyde (MDA) Content}

MDA is one of the main products of the cell membrane lipid peroxidation, its accumulation is the performance of free radical toxicity [11], MDA quantity can not only indirectly reflect the plant tissue antioxidant capacity, but also represent the degree of membrane lipid peroxidation in a certain extent. Therefore, MDA content is a very important index in plant senescence physiology and physiological research.

The testing steps of MDA content were as follows: weighed $1 \mathrm{~g}$ leaves of maize seedlings, cut it into shear, then added $2 \mathrm{~mL} 10 \%$ three chloroacetic acid (TCA) and a small amount of quartz sand, grinded into homogenate, then added $8 \mathrm{~mL}$ TCA for further grinding. The homogenate used centrifuge to centrifugal $10 \mathrm{~min}$ in 4000 rpm, took the supernatant as the sample extraction. Drew $2 \mathrm{~mL}$ the centrifugal supernatant (contrast part put 2 $\mathrm{mL}$ of distilled water), added $2 \mathrm{~mL} 0.6 \%$ thiobarbituric acid (TBA) solution, after shaking it, put it in a boiling water bath $15 \mathrm{~min}$ for fully react. Then rapid cooled it after centrifugation $10 \mathrm{~min}$, took out the supernatant to determine the absorbance in $532 \mathrm{~nm}, 600 \mathrm{~nm}$ and $450 \mathrm{~nm}$ wavelength, calculated MDA content.

The calculation formula is as follows:

$$
\text { Malondialdehyde }(\text { MDA }) \text { content }=6.45 \times(D 532-D 600)-0.56 \times D 450
$$

where $D 532, D 600$ and $D 450$ are respectively the absorbance under the corresponding wave.

\subsection{Bacteriostatic Experiments of Seed Coating Agent in Lab}

Large plaque bacteria, sheath blight fungus and maize head smut fungus are several main harmful bacteria that restrict maize yield [12] [13]. Maize large leaf spot occurred mainly on the growth of maize seedling leaves. The pathogens harm seedling leaf, leaf sheath and outer bract. Leaves appear green gray spots on early onset, multi spots connected pieces later, then the leaves turn yellow and withered, it seriously affect the normal growth of maize seedlings. Sheath blight occurred mainly in the development of the whole process of maize growth, the pathogens harm seedlings leaf sheaths, bract and ear. Firstly, the leaf sheath get disease, then appear green spots, when it become serious, it can cause stalk rot, ear rot and lodging, which seriously affect maize yield. Head smut occurred mainly in panicle stage of maize growth. The pathogens harm tassel and ear, the tillering were clustered, plants were dwarf, shortened internodes, leaf color became dark green, when it get seriously, the whole plant won't have any harvest.

In this test, we put maize large plaque bacteria, sheath blight fungus and maize head smut fungus as the research objects, used the medium culture them to determine the maize seedling growth rate respectively, which can measure the bacteriostatic effect of the novel environmental friendly maize seed coating agent $4 \#-1$ and the traditional one Shileshi. The maize seeds are coated with the self-made maize seed coating agent and Shileshi respectively according to $1: 50(\mathrm{w} / \mathrm{w})$ proportion, then put them into PDA medium. The experiment set up a 
blank group as contrast, which marked as CK. After the Petri dish being treated with high temperature and high pressure, we put the culture medium into them, then we inoculate equal amount of maize large plaque bacteria, sheath blight fungus, maize head smut fungus into each Petri dishes. Finally, put the Petri dish into temperature and humidity incubator, whose temperature at $(27 \pm 1)^{\circ} \mathrm{C}$ and humidity at $85 \%$, to culture the seed. By using colony cross method to measure the diameter, we could calculate the antibaterial rate through the diameter [14], the calculation formula is as follows:

$$
A R(\%)=\frac{A-B}{A} \times 100 \%
$$

where $A$ and $B$ are the colony diameter of the contrast group and the treatment group respectively.

\section{Results}

\subsection{Physicochemical Property Testing Results of Maize Seed Coating Agent}

The physicochemical property testing results of the novel maize seed coating agent were shown in Table 2. It showed that all the indexes of this environment friendly maize seed coating agent have reached the qualified level.

\subsection{Effect of Different Seed Coating Agents on Several Major Maize Seedling Activity Indexes}

\subsubsection{Effect of Different Seed Coating Agents on Maize Seedling Root Activity}

The root system of plant is not only the main absorptive organ of water and fertilizer nutrients, but also the important assimilate organ of substance transformation and synthesis, its growth condition is directly related to the plant life activities [15].

Effects of different seed coating agents on root activity were shown in Figure 1. The results showed that comparing with the blank group, the root activity of maize seedling was improved via the seed coated by different seed coating agents. The maize seedlings root activity of $4 \#-1$ on the third day, the fifth day and the seventh day were 2.2, 2.3, 2.5, the Shileshi group were respectively 2, 2.1, 2.2, root activity of 4\#-1 were relatively higher than the Shileshi group about 10\%, 9.52\%, 13.64\%. The improvement of maize seedling root activity may be caused by this self-made polysaccharide polymer, it can change root cell membrane structure to reduce the permeability of cell membrane and enhance the cell membrane stability. It can also activate the enzyme activity that is related to absorpt mineral nutrition in cell membrane, which can improve the ability of absorbing mineral elements. Maize growth is built on the basis of various nutrients absorbed from the roots and this can improve its various life activities in return [10].

\subsubsection{Effect of Different Seed Coating Agents on Maize Seedling Chlorophyll Content}

Effects of different seed coating agents on chlorophyll content were shown in Figure 2. We can see from Figure 2 that the total chlorophyll in maize seedlings leaves of $4 \#-1$ on the fifth day, the seventh day were improved in different degrees compared with the Shileshi group. The maize seedlings chlorophyll content of $4 \#-1$ on the fifth day and seventh day were 1.9, 2.3, while the Shileshi's were respectively 1.8 and 2, the chlorophyll content of 4\#-1 were relatively higher than the Shileshi group about $5.56 \%$ and $15 \%$. The increasing of chlorophyll content improved the light to capture pigment of chloroplast in unit leaf area and the center pigment quantity of the photosynthetic reaction. With the content of light capture pigment increasing, the leaves absorb more light, so the increase of chlorophyll content were in favor of maize leaf photochemical efficiency and photosynthesis, it promoted the accumulation of photosynthetic products and seedling growth in return [10].

\subsubsection{Effect of Different Seed Coating Agents on Maize Seedling Malondialdehyde (MDA) Content}

The effect of different seed coating agents results on maize seedling MDA content were shown in Figure 3. It can be seen from Figure 3 that the 4\#-1 coating agent can effectively reduce the MDA content in newborn root cells. The maize seedlings MDA content of $4 \#-1$ on the third day, the fifth day and the seventh day were 1.9, 2.7, 3.2, the Shileshi's were respectively 2.2, 3.1, 3.9. The MDA content of 4\#-1 compared with Shileshi's were relatively decreased about $13.64 \%, 12.90 \%, 17.95 \%$. MDA is a typical index of cell membrane lipid peroxidation, 
Table 2. Physicochemical property testing results of maize seed coating agent.

\begin{tabular}{cc}
\hline Indicators & Requirements \\
\hline pH Value & 6.0 \\
Floating Rate/\% & 95 \\
Sieve Analysis/\% & 99 \\
Viscosity & 380 \\
Film-Forming Property & qualified \\
Coating Uniformity & 95 \\
Coating Peeling Rate & 2.5 \\
Storage Stability & qualified \\
\hline
\end{tabular}

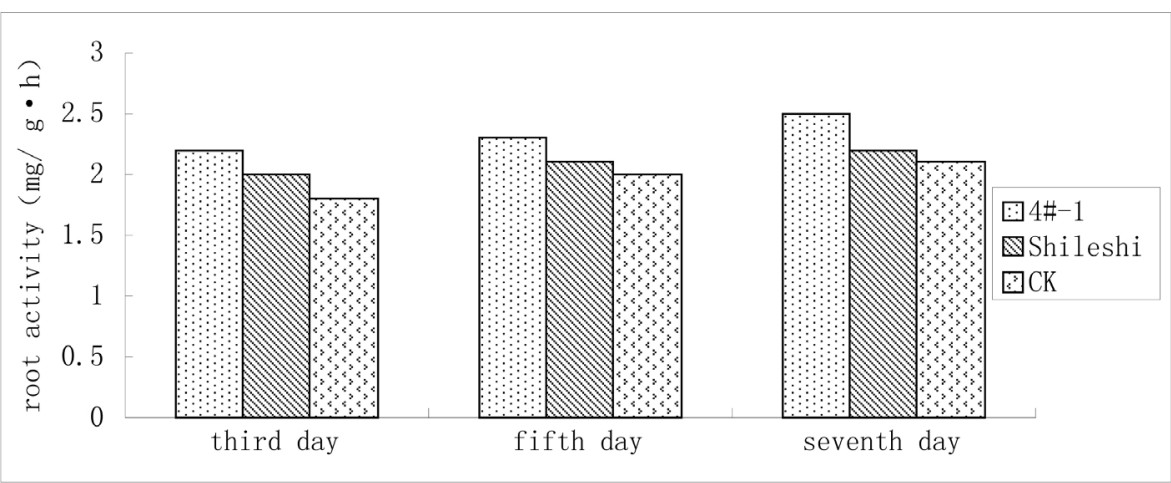

Figure 1. Effect of different seed coating agents on root activity of maize seedling.

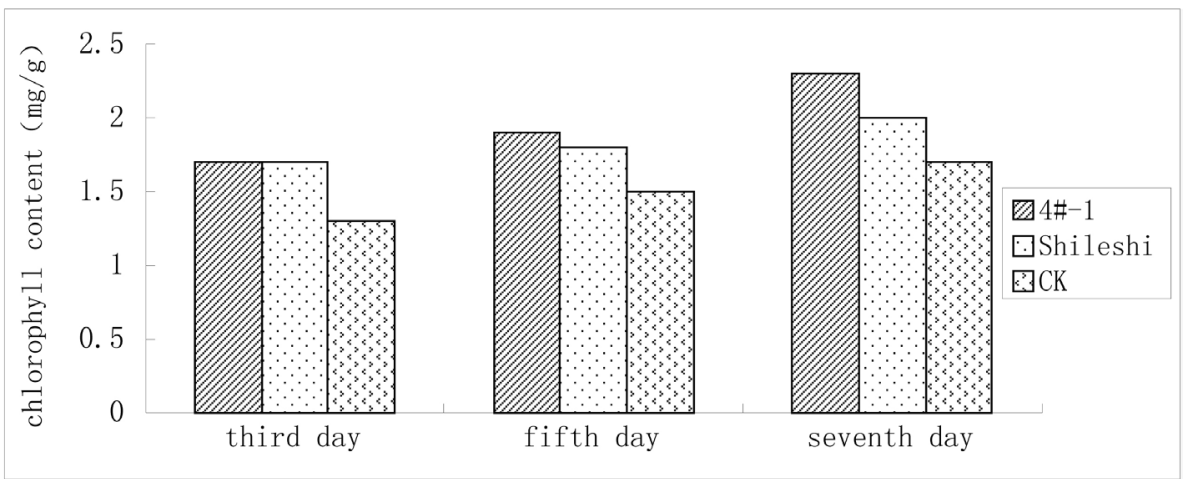

Figure 2. Effect of different seed coating agents on maize seedling chlorophyll content.

its content level is closely related to the stability of cell membrane structure, membrane material exchanges in and outside the cell membrane and the activity level of each enzyme on the cell membrane. The decrease of MDA content can reduce the lipid peroxidation products and protect biological membrane systems. It is extremely useful for alleviate some of the damage [10].

\subsection{Bacteriostatic Experiment Results of Different Seed Coating Agents in Lab}

The experiment results of $4 \#-1$ and Shileshi seed coating agent on maize big spot pathogen, sheath blight fungus and head smut fungus were shown in Table 3. From the table, we knew that both 4\#-1 and Shileshi had different degrees of improvement in inhibiting those funguses. The antibacterial effect of $4 \#-1$ is higher than the Shileshi, its inhibition rate of maize big spot pathogen, sheath blight fungus and head smut fungus have reached $88.12 \%$, 


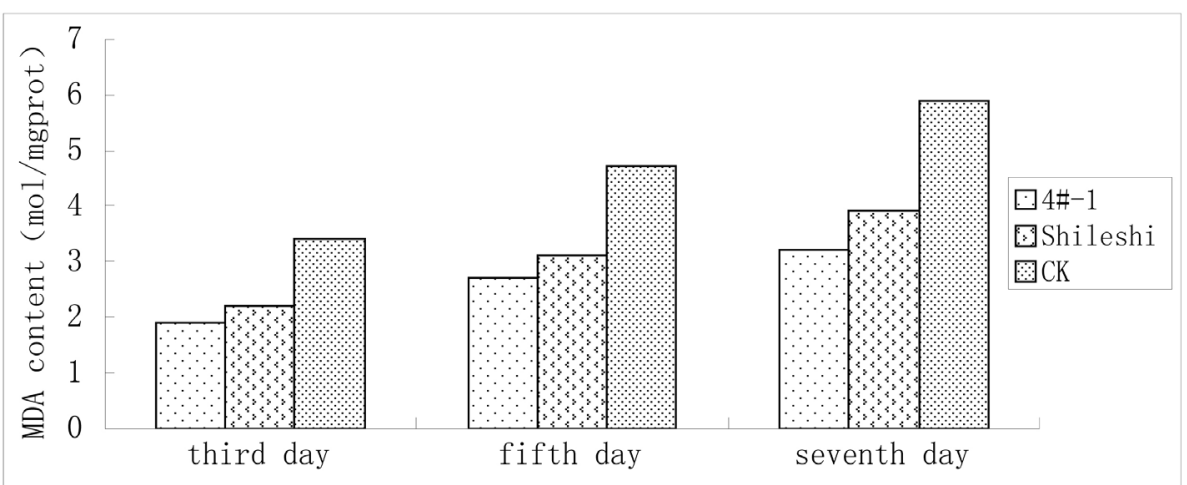

Figure 3. Effect of different seed coating agents on maize seedling MDA content.

Table 3. Bacteriostasis experiment results of different seed coating agents in lab.

\begin{tabular}{|c|c|c|c|c|c|c|}
\hline \multirow{2}{*}{$\begin{array}{l}\text { Treatment } \\
\text { Group }\end{array}$} & \multicolumn{2}{|c|}{ Large Plaque Bacteria } & \multicolumn{2}{|c|}{ Sheath Blight Fungus } & \multicolumn{2}{|c|}{ Head Smut Fungus } \\
\hline & $\begin{array}{c}\text { Colony } \\
\text { Diameter/mm }\end{array}$ & $\begin{array}{c}\text { Bacteriostatic } \\
\text { Rate/\% }\end{array}$ & $\begin{array}{c}\text { Colony } \\
\text { Diameter/mm }\end{array}$ & $\begin{array}{c}\text { Bacteriostatic } \\
\text { Rate/\% }\end{array}$ & $\begin{array}{c}\text { Colony } \\
\text { Diameter/mm }\end{array}$ & $\begin{array}{c}\text { Bacteriostatic } \\
\text { Rate/\% }\end{array}$ \\
\hline $4 \#-1$ & 5.3 & 88.12 & 4.6 & 89.38 & 4.1 & 90.21 \\
\hline Shileshi & 9.7 & 78.25 & 9.1 & 78.98 & 9.6 & 77.09 \\
\hline CK & 44.6 & - & 43.3 & - & 41.9 & - \\
\hline
\end{tabular}

89.38\%, 90.21\% respectively. It was visible that the self-made maize seed coating agent $4 \#-1$ can effectively restrain harmful fungus in maize growth and reduce the incidence rate of seeds and plants.

\subsection{Antibacterial Mechanism Analysis}

When compared with traditional maize seed coating agent Shileshi, this novel environmental friendly maize seed coating agent 4\#-1 had obvious advantage in improving antibacterial rate. This was mainly due to chitosan was added into this novel seed coating agent. By studying and summarizing, we got to know that there were two mechanism analysis of antimicrobial activity of chitosan.

First, the bacteriostasis effect was achieved by chitosan interfer with cell membrane. Chitosan form a very thick protective layer outside of seed cell when it was in high concentration, which hinder the cells to absorb nutrients [16], it can combine negative ions on the cell wall when in low concentration, such as fat polysaccharide and protein, which make cells in low stability and result in a leakage of intracellular nutrients [17]. In addition, the low degree of polymerization and low molecular chitosan are able to penetrate into the cell membrane, combine with cytoplasm, hinder the transcription of mRNA, which make the bacteriostatic function become true [18].

Second, the chitosan's destruction to the cell wall. The chitinase activity of pathogenic fungi will be stimulated by chitosan. When the chitosan concentration is very high, chitinase of fungus will be excessive expressed, which leads to chitin degradation of its own cell wall, thereby damages cell wall [19].

\section{Conclusion}

This study is built on a series of contrast experiments on the self-made environmental friendly maize seed coating agent 4\#-1 and the traditional maize seed coating agent Shileshi. We tested the maize seedling root activity and some other parameters after the maize seeds were coated with different kinds of maize seed coating agent. The results showed that the self-made maize seed coating agent 4\#-1 can effectively promote the maize root growth, increase maize seedlings chlorophyll content, reduce MDA content and inhibit a variety of maize bacteria. The environmental friendly maize seed coating agent can obviously increase maize ability to adapt outside environment and promote healthy growth of maize seedlings. 


\section{References}

[1] Liu, Z.H., Xu, Y.W. and Shang, Y.J. (2010) Discuss on How to Improve the Quality of Pesticide Exposure. Seed Science and Technology, 8, 9-11.

[2] Liu, P.F., Liu, X.L., Mu, K.G., Bai, J.J., Wu, H.X. and Wu, H.Y. (2000) Selection and Effects of Different Bentonite as Thickening Agent of Seed Coating Formulation. Journal of Pesticide Science, 2, 62-67.

[3] Wu, X.H., Liu, X.L., Wang, H.M. and Gao, R.J. (2003) The Progress and Study of Seed Coating Agent in China. Journal of Pesticides, 5, 26-28.

[4] Li, L. (2008) Different Seed Coating Agent on the Influence of Corn Head Smut. Seeds World, 11, 24.

[5] Wang, X.M., Dai, F.C. and Liao, Q. (2002) Manual of Corn Diseases and Insect Pests in the Field. China Agricultural Science and Technology Press, Beijing, 22-23, 95-95.

[6] Sha, H.L., Sha, H.Z., Fang, S.Q., Jin, Q.M. and Li, H. (2004) Control Effect of 6.9\% Corn Seed Coating of IsofenphosMethyl Triadimefon and Tebuconazole on Hypogeous Pests and Corn Smut. Journal of Jilin Agricultural University, 26, 438-440, 444.

[7] He, X.Y., Kong, Q.Q. and Xi, X.M. (2008) Security Testing of 20\% ke·fu·cuo Seed Coating Agent on Different Maize Seeds. Inner Mongolia Agricultural Science and Technology, 5, 60-61.

[8] Lei, X.T., Pan, F.X. and Zhang, Y.M. (2007) Effects of Maibao Seed Clothing Agent on the Wheat Seed Vigor and Seedling Character. Journal of Henan Institute of Science and Technology, 35, 8-10.

[9] TeKrony, D.M. (2006) Seeds: The Delivery System for Crop Science. Crop Science, 46, 2263-2269. http://dx.doi.org/10.2135/cropsci2005.12.0445

[10] Zeng, D.F. and Tu, R.J. (2011) Preparation and Study of an Environmentally Friendly Seed-Coating Agent for Cucumber. Frontiers of Agriculture in China, 50, 328-332. http://dx.doi.org/10.1007/s11703-011-1103-5

[11] Wang, J.S., Guo, C.R. and Zhang, Y. (1997) Agricultural Biological Chemical Technology. Science and Technology Press, Taiyuan.

[12] Lei, C.L. and Wang, M.Q. (2008) Central China Insect Research. China Agricultural Science and Technology Press, Beijing, 258-264.

[13] Wan, B.M. (2009) Summer Maize and Its Common Diseases Prevention and Treatment. Journal of Seed Industry Tribune, 8, 34.

[14] Zhao, B. and He, S.J. (2002) Microbiology Experiment. Science Press.

[15] Benhamou, N. (1992) Ultrastructural and Cytochemical Aspects of Chitosan of Fusarium oxysporum f. sp. radicis-lycopersici, Agent of Tomato Crown and Root Rot. Phytopathology, 82, 1185-1193.

[16] EI-Ghaouth, A., Arul, J., Asselin, A. and Benhamou, N. (1992) Antifungal Activity of Chitosan on Two Post-Harvest Pathogen of Strawberry Fruits. Phytooath, 82, 398-402.

[17] Young, D., Köhle, H. and Kauss, H. (1982) Effect of Chitosan on Membrane Permeability of Suspension-Cultured Glycine max and Phaseolus vulgaris Cells. Plant Physiology, 70, 1449-1454. http://dx.doi.org/10.1104/pp.70.5.1449

[18] Hadwinger, L.A., Kendra, D.F., Fristensky, B.W. and Wagoner, W. (1986) Chitin in Nature and Technology. Springer US, New York.

[19] Li, J.Y. and Li, H.Y. (2002) Bacteriostasis of Chitosan to Peach Brown Rot Fungus. Journal of Electron Microscopy, 21, 38-140. 
Scientific Research Publishing (SCIRP) is one of the largest Open Access journal publishers. It is currently publishing more than 200 open access, online, peer-reviewed journals covering a wide range of academic disciplines. SCIRP serves the worldwide academic communities and contributes to the progress and application of science with its publication.

Other selected journals from SCIRP are listed as below. Submit your manuscript to us via either submit@scirp.org or Online Submission Portal.
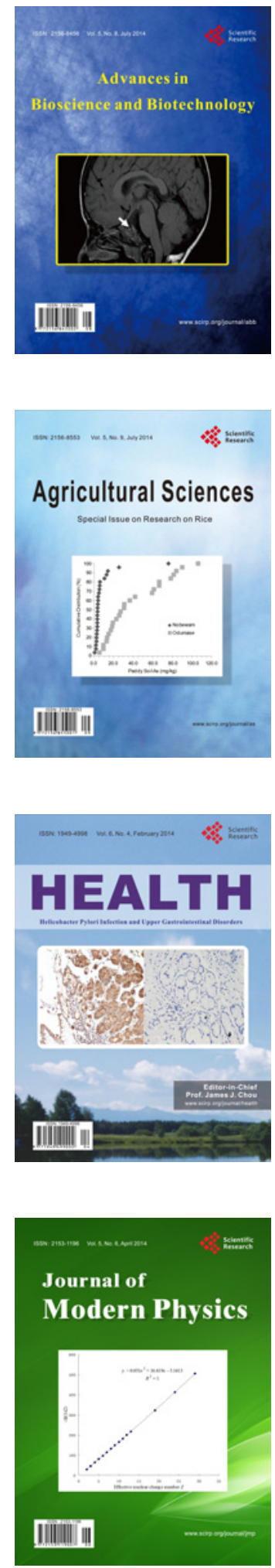
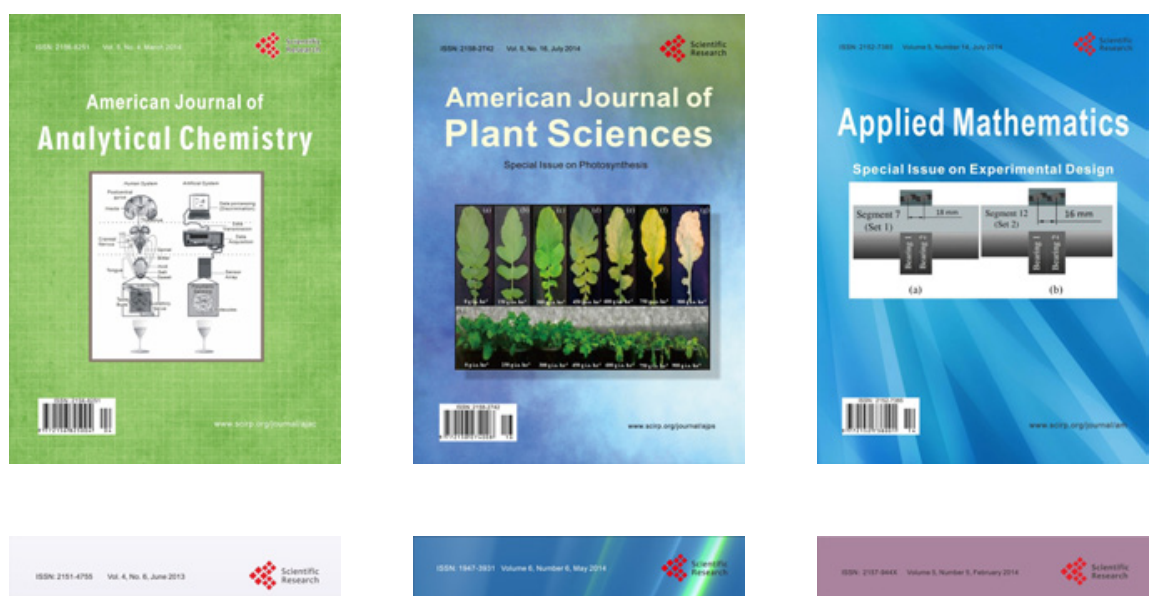

Creative Education
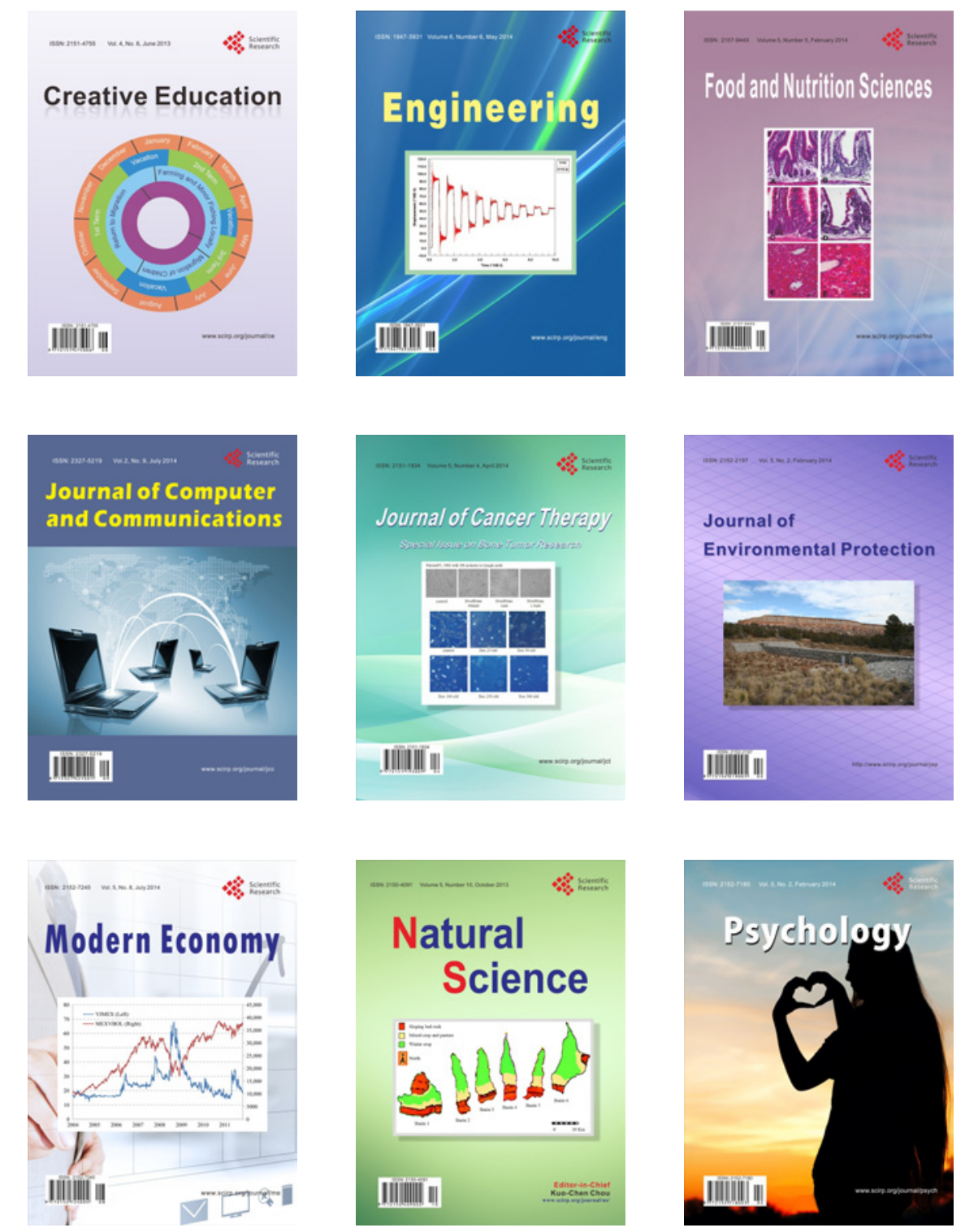